\title{
2. SOME ASPECTS OF DEVELOPING MUSICAL THINKING IN THE TRAINING OF MUSICAL STUDENT
}

Margarita Tetelea ${ }^{2}$ Ana Glebov ${ }^{3}$

\begin{abstract}
This article examines various approaches and methods used to develop musical thinking in students. It also reveals some of the principles, developed by a number of scientists to facilitate the process. One of the new principles of developing musical thinking is internalization of music, proposed by the Moldovan professor and musicologist Ion Gagim, who in his works justifies its use from the philosophical, musicological, psychological and pedagogical perspectives.
\end{abstract}

Key words: musical thinking, internalization of music, principles, methods, pedagogy of hearing

\section{Introduction}

The main objective in training children at the music school is their preparation for creative activity. The existing training traditions greatly contribute to the development of a creative personality, but they have a number of negative aspects. One of them is the fact that students who graduate from music school should become lovers of music, even if they do not become professionals. This means that the school has to develop the students' need for music, and consequently the ability to understand the language of music, to think in musical images, develop emotional experience to perceive music.

The issue of musical thinking is actively investigated in music psychology and pedagogy. There are numerous monographs and articles, which tackle various aspects of this unique ability of the human being, in general, and of the musical student, in particular. Moreover, practically the entire theoretical musicology, from melody and rhythm to form and drama, concerns musical thinking, revealing its different aspects. Music theory sheds light on the content of musical thinking, or is somehow included in it. When speaking of musical thinking, most researchers mean, almost exclusively, the creative activity of the composer and pay less attention to the problems of musical thinking of the performer or listener, in our case, of the musical student.

\section{Discussions}

In musicological works, there are two major components of musical thinking: reproduction, associated with the perception and analysis of the existing piece of music, and production, underlying the process of creation of a new piece of music (M. Aranovskiy, N. Sochor, etc.). Perception and analysis of music is the most comprehensive musical activity. It is important both as an independent activity of listening and comprehension, as well as part of any kind of creation of music. Therefore, naturally, it has a leading role in musical

\footnotetext{
${ }^{2}$ Associate Professor PhD, „Alecu Russo” State University from Bălţi, Republic of Moldavia, email: mtetelea@yahoo.com

${ }^{3}$ Lecturer PhD, „Alecu Russo” State University from Bălţi, Republic of Moldavia, email: annagl1982@mail.ru
} 
education. Most of the research, carried out in line with the study of the formation of musical skills, as well as with cognitive and communicative function of music, is devoted to it.

Musical perception is a complex sensory, emotional and intellectual process of learning and assessing a piece of music. The complexity of musical perception is apparently the reason that, so far, neither musicology, nor psychology, or pedagogy offer a single universally accepted term for it. It is called "musical perception", "listening to music", "intellectual perception", "reflection on the music by the human being", "development of music", etc. The most appropriate term for us is "musical perception and thinking" (V. Medushevskiy), as it accurately reflects the specifics of the process under study.

In the literature of the late 20-th century, the problem of musical perception and thinking has been studied mainly from the pedagogical perspective, which can be explained by the objectives of musical education in schools. Such scientists as B. Asafiev, V. Schatskaya, A. Castaliskiy, V. Karatygin, N. Grodzenskaya greatly contributed to its development. Their works identify the objectives and content of "listening to music" as a musical activity, and reveal some of the principles and methods of development of musical perception and artistic taste in schoolchildren. Later, this line was developed in the "Program of musical education for secondary schools" developed by D. Kabalevskiy, as well as in the works of O. Apraksina , E. Abdullina, V. Ostromenskiy, I. Gagim and a number of other authors.

Nazaikinskii E. believes that "musical perception is directed at comprehension and realization of those values that music as art, as a special form of reflection of reality, as an aesthetic artistic phenomenon has" ${ }^{4}$. It is determined by a system of determinants: the piece of music, the common historical, life, genre and communicative context, external and internal (personal) conditions. Musical perception, as ascertained by B. Asafiev, organizes the organized by (the composer) movement for the second time. This organization is associated with musical and life experiences of the individual.

$\mathrm{V}$. Medushevskiy in his works analyzes the modern scientific context of musical perception and thinking; he defines the concept of an "adequate perception" of a piece of music; he also proposes the theory of duality of musical form. In the modern approach to the problem of musical perception, the idea of passivity of the process has been replaced by the thesis of its active nature. Revealing the personal sense of a musical work is regarded as a prerequisite for its full perception. The thesis of the ambiguity of the meaning of a piece of art, the multiplicity of its principal performing, musicological and auditive interpretations became widely accepted. Adequate perception means seeing in the text, not only the musical, language, genre, stylistic and spiritual principles of cultural values, but also a deeply personal meaning.

V. Medushevskiy speaks of two layers of the content in a piece of music: "the layer of the nearest" and "the layer of further" values. The "nearest" values

\footnotetext{
${ }^{4}$ Nazaikinskii E. Musical Perception as a Problem of Musicology. The perception of music. Moscow, 1980
} 
is a layer of explicit meaning that is fixed in the form of the musical intonation. The "nearest" content is heterogeneous: along with a unique "thematic" content, it also includes the generalized content of style and of genre. The "further" values is a layer of deep socio-cultural interpretations of a musical piece that arise in the interaction of the "nearest" music content with the cultural and historical context of the personal life of the listener. The dialectics of the "nearest" and the "further" contents hides the source of individual auditive creativity.

These studies allow us to state again that musical thinking lies at the basis of creativity development of the individual, which is the most important goal of music pedagogy. This direction gives rise to a certain methodology of musical thinking in a variety of teaching environments. M. Kushnir has developed a comprehensive methodology of musical thinking development, based on such principles as: "the principle of integrity, the principle of vigorous activity, the principle of creativity, the principle of mental hearing" 5 .

M. Mikhaylov in his methodology of musical thinking development reveals some of the mechanisms of its development, such as intonation bank, inner-auditory background, thus making them as an essential condition for "creative, performing and thinking audition"'. V. Bobrovskiy, identifying various principles of musical and thematic thinking, believes that all the participants of musical communication possess it, thus "not only the composer, but also the singer and the listener have this thinking" .

All of the above-mentioned ideas are fundamental to the concept of contemporary music education in Moldova. I. Gagim is one of the authors of this concept, who considers music not only in terms of its aesthetic or artistic quality, but also as a way to penetrate deeper into music itself and deeper into the personality, to the level when its merges with the fundamentals of internal space" ${ }^{8}$. In this context, the scientist is developing a new and original concept: the development of student's spirituality through the internalization of music.

While acknowledging the correctness of all the previous ideas, associated with the development of musical thinking, I. Gagim believes that certain postulates should be updated and developed, involving the latest achievements of various sciences, directly connected to music through such categories as vibration, sound, movement, time, energy, i.e., basic constituents of the universe. The scientist proposes to implement them through a system of musical and pedagogical laws, methods, principles and methods.

In this context, it is first, necessary to correctly put the emphasis and clarify the "object" of research, which should not be "Music", as it has

\footnotetext{
${ }^{5}$ Kushnir M. (1986), Complex Methodology of Musical Thinking Development. Problems of development of music education: St. tr. 87 / GMPI Gnesin. Moscow

${ }^{6}$ Mikhaylov M. (2002), Methodological Culture of the Teacher and Musician. On some psychological mechanisms of musical thinking. Ed. E. Abdullina. Publishing Center „Academy", Moscow

${ }^{7}$ Bobrovskiy V. (1989), Thematism as a Factor in the Musical Thinking: Essays: In 2 vol. Vol. 1. Moscow Ed. „Muzyka"

${ }^{8}$ Gagim I. (2004), Music as a Great Pedagogy. Musical and pedagogical education at the turn of the century. Proceedings of the VIII International Conference. Moscow
} 
traditionally been, but "Music and I", which is the ratio between the person and "this great phenomenon of the world and of the human spirit". According to the scientist, this fundamentally changes the state of affairs, as in the process of studying of the music, no matter how good and deeply it is done, the music still remains outside man. The development of musical thinking through the direction of musical and educational activities only towards "Music", limits the process only to acquiring knowledge about music (it becomes informative, extroverted, the work is "superficial"). However, in the implementation of the relationship "Music and I", according to the scientist, the activity becomes introvert, it must be realized "inside of the music" and „I" finally merges , or is identified with the music" 10

The above concept, developed by I. Gagim, allowed him to review the methodology of musical thinking, and to formulate the principle of internalization of music, which means "transfer of music from the outer to the inner world, transforming it from a sound and physical substance (energy) into a psycho-spiritual one. In the internalization of music (one's identification with music) all of our inner consciousness comes into the state of music, which is not an ordinary, but a transformed state (with a plus sign in the case of real music and with a minus sign in the case of anti-destructive music" ${ }^{\prime 1}$. The psychological concept of the state of music, formulated by I. Gagim, resonates with the psycho-musicological concept modus state, formulated by E. Nazaikinskiy ${ }^{12}$.

The scholar proposes to implement the principle of internalization of music by means of such methods as: thoughtful singing; plastic intoning with simultaneous mental tracking of sonic line (vox mentis - mental voice), "meditative" listening; humming the melody in a low voice, with a gradual transition to a "silent" singing. Thus, "music lies at a the bottom, or is the basis of the "I", becoming the inner living energy, which sounds as a multitude of tunes, lying in the depths of consciousness, filled with feelings, directing the thoughts, actions and deeds" 13 . These findings allowed the scientist to state that musical education is the cradle of pedagogical science, as well as to put forward the following postulate "Music is Great Pedagogy" 14 .

However, according to the author, music is not a usual Pedagogy: It is the Pedagogy of Hearing. Other genres of pedagogy involve the pedagogy of vision; they are based on the vision and acquisition of the visible world. While the hearing is the representative of a hidden, but deeper world. In comparison with the vision, it requires more engrossment, concentration of the internal forces, and greater activity of imagination to detect the invisible sense. (Holy Scripture: when Light appeared at the command of God, there was already a "rumble, sound" over the abyss. Additionally, God sent His messages to Moses, David, Jesus, and others in audible/audio forms. The Scripture mentions the need for

\footnotetext{
${ }^{9}$ Gagim I. op. cit.

${ }^{10}$ Ibidem

${ }^{11}$ Ibidem

${ }^{12}$ Nazaikinskiy E. (1982), Logics of Musical Composition, Moscow

${ }^{13}$ Gagim I. op. cit.

${ }^{14}$ Ibidem
} 
listening and obedience; to be obedient means to listen/acquire wise rules of life. In the pre-Socrates philosophy, the ideas were perceived by hearing: to contemplate ideas meant to hear them. Additionally, a pre-born child first hears in the womb, and only after the birth he can see. Psychologists say that the lack of hearing has a greater negative impact on the formation of the psyche/consciousness of the child than the absence of vision; creating the sound image is one of the highest levels of activity of the human consciousness.

\section{Conclusions}

These judgments allow us to state that musical education is part of Pedagogy of Hearing. As I. Gagim states, "it (education) leads to a particular type of knowledge of the world and of the human being - musical knowledge: cognition through the prism of laws of music, its perfect categories; vision of the world through the eyes of the music" 15 Based on the statements of the scientist, we can say that an original thinking/ consciousness is developed in the process of internalization of music, it is associated with a particular philosophy - the philosophy of sound, as one of the highest form of wisdom. The establishment of the Pedagogy of Hearing with its essential opportunities to educate the "inner part" of the human being, is an urgent need in the present time of spiritual wandering.

\section{References}

1. Bobrovskiy, V. (1989). Thematism as a Factor in the Musical Thinking: Essays, vol. 1. Moscow: Muzyka

2. Dys, L. (1989). Musical Thinking: the Nature, Categories, Aspects of the Study. Musical Thinking as an Object of Study: Ukraine: Coll. Art./-K.: Moose.

3. Gagim, I. (2004). Music as a Great Pedagogy. Musical and pedagogical education at the turn of the century. Proceedings of the VIII International Conference

4. Gertsman, E. (1986). Ancient Musical Thinking. Leningrad

5. Kushnir, M. (1986). Complex Methodology of Musical Thinking Development. Problems of development of music education: Moscow: St. tr. 87/GMPI Gnesin

6. Mikhaylov, M. (2002). Methodological Culture of the Teacher and Musician. On Some Psychological Mechanisms of Musical Thinking. Moscow: Academy Publishing Center

7. Nazaikinskiy, E. (1972). On the Psychology of Musical Perception. Moscow

8. Nazaikinskiy, E. (1982). Logics of Musical Composition. Moscow

9. Podurovskiy, V., Suslova N. (2001). Psychological Correction of Musical and Pedagogical Activities. Moscow

10. Tarasova, K. (1988). Ontogeny of Musical Abilities (Pedagogical Science Reforms in School) / Nauch.-research. Moscow: Institute of preschool education Acad. ped. Sciences of the USSR

${ }^{15}$ Gagim I. (2004) op. cit. 